\title{
Contribution of Leg Power, Arm Power, Stomach Muscle Power, and Back Muscle Power on Jumping Services
}

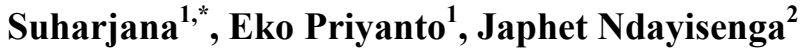 \\ ${ }^{1}$ Department of Sport Science, Yogyakarta State University, Indonesia \\ ${ }^{2}$ Institute of Physical Education and Sports Bujumbura, University of Burundi, Burundi
}

Received July 20, 2020; Revised September 16, 2020; Accepted September 29, 2020

\section{Cite This Paper in the following Citation Styles}

(a): [1] Suharjana, Eko Priyanto, Japhet Ndayisenga , "Contribution of Leg Power, Arm Power, Stomach Muscle Power, and Back Muscle Power on Jumping Services," International Journal of Human Movement and Sports Sciences, Vol. 8, No. 5, pp. 240 - 248, 2020. DOI: 10.13189/saj.2020.080512.

(b): Suharjana, Eko Priyanto, Japhet Ndayisenga (2020). Contribution of Leg Power, Arm Power, Stomach Muscle Power, and Back Muscle Power on Jumping Services. International Journal of Human Movement and Sports Sciences, 8(5), 240 - 248. DOI: 10.13189/saj.2020.080512.

Copyright $\mathrm{C} 2020$ by authors, all rights reserved. Authors agree that this article remains permanently open access under the terms of the Creative Commons Attribution License 4.0 International License

\begin{abstract}
Background: Service jumping is one of the volleyball techniques which is very important to be trained in the game in order to complicate the opponent reception. Proposal: This research aims to determine the contribution of leg power, arm power, abdominal muscle strength, and back muscle strength to the volleyball athlete's jumping service ability. Method: This research is a correlational descriptive study. The subjects of this study were volleyball athletes from Bantul Regency club. The sampling technique used purposive sampling with a total of 42 respondents. Data collection instruments using measurement tests. Data analysis used multiple regressions. The results showed that there was a contribution of leg power to the volleyball athlete's jumping service ability ( $\mathrm{p}$ value $=0.011$ ) with a contribution of $28.7 \%$. There was a contribution of arm power to jumping service ability in volleyball games ( $p$ value $=0.015)$ with a contribution of $20.4 \%$. There was a contribution of abdominal muscle strength to the volleyball athlete's jumping service ability ( $p$ value $=0.018$ ) with a contribution of $23.2 \%$. There was a contribution of back muscle strength to the volleyball athlete's jumping service ability during games $(\mathrm{p}$ value $=$ 0.031 ) with a contribution of $16.7 \%$. There was contribution of leg power, arm power, abdominal strength and back muscle strength to the volleyball athlete's jumping service ability ( $p$ value $=0,000$ ). The amount of contribution of leg power, arm power, abdominal strength
\end{abstract}

and back muscle strength to jumping service ability is $89 \%$. Conclusion: a volleyball training must be complete because its techniques include the whole body.

Keywords Leg Power, Arm Power, Abdominal Muscle Strength, Back Muscle Strength, Service Jumping

\section{Introduction}

Volleyball has established itself as a very popular sport among the people of Indonesia. The consequence of public opinion is people's demand for the optimal performance of volleyball players in Indonesia. Volleyball coaches and coaches are always required to carry out training programs that touch sports science in accordance with current sport developments [1].

Optimal performance can be achieved by coaching. The pattern of achievement sports development in general can be described as a pyramid form where the number of athletes with volleyball achievements is very small, because the population is spread throughout Indonesia with limited guidance in the regions. This indicates that the peak sports achievements will be achieved on the basis of potential and talented sports coaching activities so that the results are more optimal [2]. 
The basic techniques that must be mastered in volleyball games are service, blocking, and spikes mentioned techniques with the ball including service, passing, bait / set-up, smash, and block [3]. While some research revealed there are four basic techniques for playing volleyball. The first is passing, including passing up, passing down, and set-up bait. Second is service which includes lower hand service, and upper hand service. Third is smash, which includes normal smash, semi smash, and push smash. The fourth is a dam or block, which includes a single block and a friend block [4].

Service is one of the basic techniques that is very important and must be mastered by a volleyball player. Servicing is a blow to the opponent's area. based on that paradigm, service is the first opportunity to bring down an opponent and make the opposing team lose their rhythm. Servicing the ball simply over the net is not enough for a team that wants to win in the championship. There are several factors that characterize a team with good service. First is the determination of the right service for each player. Furthermore, for effective service, servers need to be mentally aggressive and have strong hand contact [5]

One popular type of service used by volleyball athletes is jumping service. The service movement jumps into three stages. First is the initial attitude, which is standing in the service area near the rear line facing the net, both hands holding the ball. The second is the implementation motion, which is toss the ball as high as approximately 3 meters slightly in front of the body, then lower the body by bending the knees to start jumping as high as possible then the ball is hit as high as possible like a smash. Beat the wrist as quickly as possible so that it produces a high topspin blow so that the ball as quickly as possible descends to the opponent's field. Third is the follow-up motion, which is after making a blow by reaching the ball as high as when flying when floating in the air, immediately landing on the field and immediately taking a position ready to receive returns or attacks from the opponent [6].

Good service skills require good physical conditions. Physical conditions needed in volleyball are power, strength, endurance, speed, flexibility and coordination. Performing jumping service techniques for volleyball requires the aspect of arm and leg power which is coordinated with the strength of the abdominal muscles and back muscles in an effort to prepare for hitting the ball during service jumping. Good coordination between the bio motor components will produce a good jumping service with a ball full of strength [7]. Jumping service is the most difficult service to do compared to other types of services. The jumping service is done by jumping like a smash. Coordination is an important factor in jumping. Coordination between hands and feet can produce effective service. Fast arm swings are needed in this service, whereas fast legs tend to produce fast arms. In addition, high tosses provide the opportunity for the server to produce speed by taking several steps before contact with the ball [8]

Jumping service if it is able to be done by the player perfectly can also be a tool to attack. The jumping service is not just the beginning of the game but also the beginning of the attack. The speed of the results of the service jumping service is usually harder and faster so that it will be difficult to return by the opponent, and will benefit the attacking team because it will generate points. The jumping service has a greater chance of generating points than the top service or the bottom service, although the percentage rate is not known with certainty [9]

The reality on the ground shows many cases of volleyball players who are unable to execute jumping services properly. This is seen during the game many service balls do not hit the target, some balls go too hard. This can be caused by lack of good motion coordination, lack of power and strength used in servicing so that service results are less than optimal. Ailure to service jumping, does not only occur in beginners or amateurs, even in many professional classes matches. A high level of difficulty because it requires good body coordination causes many players to fail to service jumping. Jumping service is the service with the highest error rate, it is due to the timing of the throw and when jumping near the ball [10]

Deficiency and ineffectiveness of the player in doing jumping services occur because of its complexity. Several factors cause the low level of success of players in service jumping. These factors include first, technical mastery, especially the basic ability of placing the service ball on the field. Second, players must have a high level of motor ability to support better ball placement. Jumping services require complex abilities while demanding qualified physical abilities and abilities. Athletes produce high-level strength when spiking or jumping and absorbing a lot of strength when flying, landing, or blocking a spike. Without strength, players will be weak during the game in an increasingly intense game. In addition, the capabilities possessed by players become not integrated [10]

Even though the failure rate of jumping service execution is quite frequent, there is an increase in the use of jumping services in volleyball matches. The use of jump serve in high-level volleyball tournaments from 1992 to 2002 increased from $20.8 \%$ to $99.2 \%$ [11]. The success of the jumping service will benefit the service team, because it will be the beginning of an attack on the opponent. The success of the jumping service will also be a scoring tool when the opponent is unable to return the jumping service performed by the player. Successful jumping services performed by players will support to score and achieve victory [12]. A jumping service that cannot be done properly by the player can be detrimental to the team. A jumping service failure causes the team to lose the opportunity to attack and score. Failure of the jumping service also adds to the opposing team's score so that it can be detrimental to the team because it provides additional 
scores for the opposing team.

Based on the writer's experience in the field, the team whose players are able to do jumping services will master the match. The team is able to attack and put pressure on the opposing team. Based on field observations, the percentage of successful jumping services in scoring around $85 \%$.

Based on the background of the problems outlined above, it can be concluded that the success of the jumping service requires good coordination between bio motor components. Therefore, the authors are interested in conducting research on "Donation of Leg Power, Arm Power, Abdominal Muscle Strength, Back Muscle Strength Against the Ability to Perform Jumping Services on volleyball Athletes".

\section{Materials and Research Methods}

This research is a descriptive correlational survey method with measurement tests. The aims of this study were to find whether there is a relationship, and if there is a relationship, how close the relationship is and how meaningful the relationship is. This research is said to be a correlational category because looking for data whether there is a relationship between one variable with another variable, and if there is a relationship, then look for how far the relationship is with survey data collection using the measurement test method.

\subsection{Operational Definitions of Research Variables}

The dependent variable $(\mathrm{Y})$ in this study is the ability to service jumping. Jumping service is the ability to hit the ball, which in this study was done by jumping (jump header) that is jumping up to hit the ball. Test was given the opportunity to serve three times. Value is the fall of the ball at the point of attack that has been given a previous score. Independent variables $(\mathrm{X})$ in this study included leg power (X1), arm power (X2), abdominal strength (X3), and back muscle strength (X4).

\section{Explosive Leg power}

Power is defined as the speed at which work is performed and is a product of force and displacement. Developing muscle power then calls on several variables: Explosive force, displacement and time. Indeed, these three variables may be the very essence of what defines athletic performance. Leg power is the ability of leg muscles to direct energy to jump while performing maximum jumping service in a fast and precise time. Measurement of explosive leg muscle power with a vertical power jump test. Tests make the jump $3 \mathrm{x}$ as high as possible and should not start when jumping up. The measured result is the difference between the height of the jump and the height achieved by the unit of measurement $\mathrm{cm}$.

\section{Arm power}

Arm power is the ability of the arm muscles to provide a flow of energy to generate thrust through swing when hitting the ball in the jumping service. Measurement using a medicine ball test, with the unit of measurement is the distance using the meter.

\section{Abdominal muscle strength}

Abdominal muscle strength is the ability of the abdominal muscles to make abdominal contractions to perform motion or support movement. Measurement of abdominal muscle strength is done with sit ups for 30 seconds. The assessment is the number of sit-ups with perfect movements that have been successfully tested for 30 seconds, with a unit of measurement that is the number of sit-ups that can be done.

\section{Back muscle strength}

Back muscle strength is the ability of the back muscles to provide resistance to the strength of the back muscles so that the service punch stays directed. Measurement using a back-up test for 30 seconds, with units of measurement that is the number of back-ups that can be done.

\section{Development of the Strength}

Comprehensive and well-planned volleyball training takes into account the development of all the required physicals qualities, and, among them, maximum strength and specific strength. Essential components of success, these two concepts must be worked on. Depending on the case, it will be either a separate work (indoor bodybuilding), or a development for an adapted outdoor practice: medicine ball, hurdles, plinths ... Strength training aims to give volleyers their greatest general physical possibilities, in order to put them in the best conditions to tackle or support specific training, and of course the competitive effort. Strength will be expressed in two ways in volleyball:

- $\quad$ hitting the ball (on smash and serve)

- jumps (smash and block)

The two strength development priorities will therefore focus on the upper body for the strike and on the legs for the jumps. The problem encountered at high level depends on the nature of the forces envisaged. These must be maximum throughout the match. However, this explosive force, which the volleyball player must have during a jump for example, must be able to be repeated significantly and this as close as possible to the maximum. These three aspects of strength (maximum strength, explosive and repetitive) must be worked on. The maximum strength sessions are made of exercises oriented towards a development of the constitutive factors (hypertrophy) or nervous (synchronization of the motor units). 
Specific strength sessions are made of strength work coupled with the sporting activity itself. The explosiveness will be obtained by an adapted work of dynamic force.

Weight-Building Sessions

Each weight training session can have three modalities; they will be oriented:

- $\quad$ either towards maximum force,

- $\quad$ either towards the specific force,

- or towards general reinforcement for the purpose of prevention and protection of the volleyball player.

Upper Body: I made a choice on the main exercises for the upper body and I considered the following 3 exercises as the most interesting: - the pulls - the bench presses - the pullovers. The pulls are a balancing exercise for the upper body, because they mainly work on the antagonists of the muscles of the strike. Bench presses are the essential movement for strengthening the arms and shoulder girdle (mainly the pecs and triceps). Pullovers are great for typing.

Lower Body: For the lower body, the main exercises in weight training sessions are the $1 / 2$ squat, side lunge and calves. The work of the $1 / 2$ squat and the calves corresponds perfectly to the work of the muscles of the jump. Lunge work is more Liberal specific for all defense and reception work. It is, in my opinion, important to also work the abductors and adductors favoring lateral movements.

\subsection{Population and Research Samples}

The population in this study were all athletes in the volleyball club in Bantul Regency. The sampling technique in this study was purposive sampling, which is a sampling technique using certain criteria. The criteria for this research sample are as follows: (1) The volleyball club that actively participates in regional and national level competitions; (2) Has more than 20 members; (3) Apply the same type of exercise; (4) The trainer applies a jumping service exercise; (5) Players in the club usually do the jumping service in the match (seen from direct researcher's observation). The sample in this study amounted to 42 people.

\subsection{Data Collection Instruments and Techniques}

The research instrument is a tool used to measure natural or social phenomena encountered. The instruments in this study were as follows: (1) Vertical jump test to measure leg muscle power; (2) Medicine Ball test as a tool to measure arm power; (3) Sit ups to measure abdominal muscles; (4) Back up test to measure the strength of back muscles; (5) Rusell-Lange Volleyball Test to measure jumping service capabilities.

\subsection{Data Collection Technique}

Data collection techniques are a method used by researchers to collect data. This study uses a survey method with test and measurement techniques. Survey is a research approach that is generally used for broad and extensive data collection test is a series of questions or exercises and other tools used to measure the skills, intelligence knowledge, abilities or talents of individuals or groups.

Measurement of leg muscle power with a vertical power jump test. The use of vertical jump tests to measure leg muscle power because this test has been widely used by various studies both at national and international levels as a tool to measure arm muscle power. This instrument has also been tested for validity with a test validity value of 0.923 with a reliability value of 0.960 so that it is declared eligible for research data collection. The steps to carry out the vertical power jump test are as follows (Reiman and Manske, 2009, p.151): (1) standing test sideways toward the wall, legs closed, feet fully pressed to the floor; (2) One testicle hand that is close to the wall reaches up as high as possible, feet still attached to the floor. Record high achievement; (3) jump up test as high as possible and touch the board. Record the height of the jump; (4) Done 3 times; (5) The evaluation is the difference between the height of the jump and the height of the achievement. The value used is the best result with the unit of measurement $\mathrm{cm}$.

Measuring the strength of the arm's power is done using the Medicine Ball test. The selection of the Medicine Ball test as a tool to measure arm power refers to Reiman and Manske (2009, p.131) which explains that the Medicine Ball test can be used to measure arm power. It is also strengthened by the validity of this test which has a test validity value of 0.744 with a reliability value of 0.827 . The steps for implementing the Medicine Ball test are as follows (Reiman and Manske, 2009, p.131): (1) The equipment used is a rope, chair, measuring device and a ball; (2) Testi sitting in a chair in an upright position; (3) Testi holds the ball with both hands in front of the chest and under the chin. (4) The rope is placed on the chest of the testicle and held by the partner behind the testicle to avoid movement when the testicle pushes the ball; (5) The ball is pushed with full power to reach maximum distance; (6) The test is carried out 3 times; (7) Rating is the farthest distance from 3 times the ball is thrown, measured from the chair to the point where the ball falls.

Measurement of abdominal muscle strength is done by using a sit-up test. The use of sit ups to measure abdominal muscles is based on the opinion of experts namely Ismaryati (2009, p.119) which explains the strength of the abdominal muscles can be tested using sit ups. This test has also been widely used in various studies and scientific studies by previous researchers. This test has also been declared valid with a test validity of 0.933 with a reliability value of 0.963 . The steps in taking data using sit-up tests are as follows (Ismaryati, 2009, p.119): (1) Testi perform sit-up tests; (2) The test is done repeatedly quickly without a break within 30 seconds; (3) The evaluation is the large number of sit-up movements that have been successfully 
tested for 30 seconds.

Measurement of back muscle strength is done by using the backup test. The selection of this test to measure the back-muscle strength in Reiman and Manske (2009, p.223) which mentions the use of back up tests to measure the strength of back muscles. This test has also been declared feasible based on the validity and reliability test which is obtained a test validity value of 0.968 with a reliability value of 0.984 . The steps to measure back muscle strength using a backup test are as follows (Reiman and Manske, 2009, p.223): (1) perform test a backup test; (2) The test is done repeatedly quickly without a break within 30 seconds; (3) The evaluation is the large number of back up movements that have been successfully tested for 30 seconds.

Measurement of jumping service capabilities using the Rusell-Lange Volleyball Test. Use of this test to measure the ability of service jumping with the consideration that this test was developed by experts. According to Collins \& Hodges (2001, p.288) this test has been widely used for research and training purposes. This test has been tested for validity with a validity test of 0.858 with a reliability value of 0.879 . Steps for implementing the Rusell-Lange Volleyball Test. are as follows: (1) Test preparation to conduct the test by standing behind the restraining line; (2) serve jumping test services by aiming the ball at the target area that has been given a score; (3) Testes are given 3 opportunities to do jumping services; (4) The score recorded is the sum of the 3 service jumping scores.

\subsection{Data Analysis Technique}

Data analysis techniques used in this study are the normality test, linearity test, and multiple regression analysis. Normality test to determine whether the variables in the study have a normal distribution. The test used is the Kolmogorov Smirnov test. Linearity test is performed to determine the relationship between independent variables and dependent variables in the form of linear or not. Multiple regression analysis was used to test the contribution of leg power, arm power, abdominal muscle strength, back muscle strength to the ability to service jumping in volleyball.

\section{Results}

\section{Normality Calculation}

Normality calculation is done to test whether the analyzed data has a normal distribution of data or not. Calculation of data normality was performed using the Kolmogorov Smirnov test.

Table 1 shows the results of calculating the normality of leg power data obtained a KSZ value of 0.702 and a significance value of 0.708 . In the arm power data, the KSZ value is 0.904 and the significance value is 0.388 . The analysis results on the strength of the abdominal muscles obtained KSZ value of 0.642 with a significance value of 0.805 . In the back-muscle strength data obtained KSZ value of 0.915 with a significance value of 0.373 and the jumping service data obtained the value of KSZ 1.168 with a significance value of 0.131 . All pretest data obtained significance values greater than $0.05(p>0.05)$, it can be stated that the data of this study were normally distributed. This means that the distribution of research data meets the criteria for data normality curves as a condition of parametric statistical analysis

Table 1. Data Normality Test Results

\begin{tabular}{|c|c|c|c|}
\hline Research variable & $\begin{array}{c}\text { Kolmogorof } \\
\text { Smirnov } \boldsymbol{Z}\end{array}$ & $\begin{array}{c}\text { Sig } \\
(\boldsymbol{p})\end{array}$ & Decision \\
\hline Leg Power & 0,702 & 0,708 & Normal \\
\hline Arm Power & 0,904 & 0,388 & Normal \\
\hline $\begin{array}{c}\text { Stomach muscle } \\
\text { power }\end{array}$ & 0,642 & 0,805 & Normal \\
\hline $\begin{array}{c}\text { Back muscle } \\
\text { power }\end{array}$ & 0,915 & 0,373 & Normal \\
\hline Service jumping & 1,168 & 0,131 & Normal \\
\hline
\end{tabular}

\section{Linearity Calculation}

Linearity test is used to test whether the relationship between each independent variable with the dependent variable has a linear relationship or not

Table 2. Linearity Test Results

\begin{tabular}{|c|c|c|c|}
\hline Correlation & F count & Sig $(\boldsymbol{p})$ & Decision \\
\hline $\mathrm{X} 1 \rightarrow \mathrm{Y}$ & 0,708 & 0,769 & Linier \\
\hline $\mathrm{X} 2 \rightarrow \mathrm{Y}$ & 1,286 & 0,289 & Linier \\
\hline $\mathrm{X} 3 \rightarrow \mathrm{Y}$ & 1,965 & 0,066 & Linier \\
\hline $\mathrm{X} 4 \rightarrow \mathrm{Y}$ & 1,281 & 0,300 & Linier \\
\hline
\end{tabular}

Table 2 shows that the linearity test results to test the relationship between leg power and service jumping obtained the calculated $\mathrm{F}$ value of 0.708 with a significance of 0.769 . Linearity test results to test the relationship between arm power with service jumping obtained the calculated $F$ value of 1.286 with a significance of 0.769 . Linearity test results to test the relationship between abdominal muscle strength and service jumping obtained the calculated $F$ value of 1.965 with a significance of 0.066 . Linearity test results to test the relationship between back strength and service jumping obtained the calculated $\mathrm{F}$ value of 1.281 with a significance of 0.300 .

The results of the linearity calculation of the relationship of $\mathrm{X}$ and $\mathrm{Y}$ variables obtained significance values greater than $0.05(p>0.05)$. Because the significance value is greater than $0.05(\mathrm{p}>0.05)$, it can be stated that the relationship between variables X1, X21, X3, and X4 with jumping service is linear. 


\section{Hypothesis test}

Testing the research hypothesis is done by analyzing multiple regression or multiple linear regression.

Table 3. Results of Multiple Linear Regression Analysis

\begin{tabular}{lcccc}
\hline \multicolumn{1}{c}{ Variable } & Regresion & $\mathrm{r}$ & $\mathrm{t}$ & Sig. \\
\hline Leg Power & 0,085 & 0,895 & 2,686 & 0,011 \\
\hline Arm Power & 0,881 & 0,844 & 2,556 & 0,015 \\
\hline $\begin{array}{c}\text { Stomach muscles } \\
\text { strength }\end{array}$ & 0,087 & 0,870 & 2,474 & 0,018 \\
\hline Back muscle strength & 0,037 & 0,818 & 2,247 & 0,031 \\
\hline Constant & $:-5,596$ & & & \\
\hline Adjusted $\mathrm{R}^{2}$ & $: 0,890$ & & & \\
\hline F count & $: 75,155$ & & & \\
\hline Sig. & $: 0,000$ & & & \\
\hline
\end{tabular}

$\mathrm{Y}=-5,596+0,085 \mathrm{X} 1+0,881 \mathrm{X} 2+0,087 \mathrm{X} 3+0,037 \mathrm{X} 4+\mathrm{e}$

\section{T test (partially)}

This $t$ test is a test to show the effect of individual independent variables in the model on the dependent variable. If the significance value is less than $0.05(\mathrm{p}<0.05)$, it can be concluded that the independent variable partially has a significant effect on the dependent variable. The first hypothesis proposed in this study reads "There is a contribution of leg power to the ability to service jumping in volleyball games". The results of the correlation analysis note the calculated $r$ value of 0.895 with a significance value of 0,000 . The results of the multiple regression statistical analysis on the $t$ test of leg power variable obtained $t$ value of 2.686 with a significance level of 0.011 . Because the significance is less than $0.05(p<0.05)$, the hypothesis is accepted. This means that there is a significant contribution of leg power to the ability to service jumping in volleyball games.

The second hypothesis proposed in this study is "There is a contribution of arm power to the ability to service jumping in volleyball games". The results of the correlation analysis note the calculated $r$ value of 0.844 with a significance value of 0,000 . The results of the multiple regression statistical analysis on the arm power variable $t$ test obtained $t$ value of 2.556 with a significance level of 0.015 . Because the significance is less than $0.05(p<0.05)$, the hypothesis is accepted. This means that there is a significant contribution of arm power to jumping service abilities in volleyball games. The third hypothesis of this study reads "There is a contribution of abdominal muscle strength to the ability to service jumping in volleyball games". The results of the correlation analysis note the value of $r$ count is 0.870 with a significance value of 0.000 . The results of the multiple regression statistical analysis on the $\mathrm{t}$ test for the variable abdominal muscle strength obtained $t$ value of 2.474 with a significance level of 0.018 . Because the significance is less than $0.05(\mathrm{p}<0.05)$, the hypothesis is accepted. This means that there is a significant contribution of abdominal muscle strength to the ability to service jumping in volleyball games.

The fourth hypothesis in this study reads "There is a contribution of back muscle strength to the ability to service jumping in volleyball games". The results of the correlation analysis note the value of $r$ count is 0.818 with a significance value of 0.000 . The results of the multiple regression statistical analysis on the $t$ test of the back-muscle strength variable obtained the value of $t$ count 2,247 with a significance level of 0.031 . Because the significance is less than $0.05(\mathrm{p}<0.05)$, the hypothesis is accepted. This means that there is a significant contribution of back muscle strength to the ability to service jumping in volleyball games.

\section{F test}

The fifth hypothesis proposed in this study is "There is a contribution of leg power, arm power, abdominal strength and back muscle strength to the ability to service jumping in the game of volleyball". The F test was used to prove statistically that the entire research variable used in this analysis had a significant simultaneous effect. If the significance value of $F$ is less than $0.05(p<0.05)$, the regression model is significant. The results of the analysis obtained a calculated $F$ value of 75.155 with a significance of 0.000 . Because the significance value is smaller than $0.05(p<0.05)$, the hypothesis is accepted. This means that there is an influence of leg power, arm power, abdominal strength and back muscle strength on the ability to service jumping in volleyball games.

\section{Coefficient of Determination (R2)}

The coefficient of determination is a tool to measure the percentage of the effect of the independent variable on the dependent variable. The magnitude of the coefficient of determination ranges from 0 to 1 , the closer to zero the magnitude of the coefficient of determination of a regression equation, the smaller the effect of all independent variables on the dependent variable. Conversely the greater the coefficient of determination close to 1 , the greater the effect of all independent variables on the dependent variable. The results of the analysis obtained the coefficient of determination (R2) of 0.890 . These results indicate the contribution of leg power, arm power, abdominal strength and back muscle strength to the ability to service jumping in volleyball games by $89 \%$ while the remaining $11 \%$ is influenced by other factors not examined in this study.

Based on the calculation results it is known from the total contribution of $89 \%$, leg power variable contributed $28.7 \%$, arm power variable contributed $20.4 \%$, stomach muscle strength contributed $23.2 \%$ and back muscle variable contributed $16.7 \%$. It can be concluded that the 
variable that contributed the most was leg power.

\section{Discussion}

The results of statistical analysis prove there is a significant contribution of leg power to the ability to service jumping in volleyball games ( $p$ value $=0.011$ ). This shows that leg power has an influence on the achievement of jumping service results. Leg power is an important element in jumping service. The leg power has a contribution to the ability to service jumping can be explained because the leg power is to make players able to jump when doing jumping services. Jumping or jumping is one of the most important movement components when doing jumping services. The existence of leg power gives the strength in the form of explosive power from the legs which will make the player able to jump as high as possible to reach the ball position. Leg power is also the beginning of the service movement. Leg power is the foundation of the movements of the other limbs during service. Strong leg power makes the foundation of the movement stronger and provides power when jumping. This supports the success of jumping service.

A jump during service jumping can be done if you get strong repulsion and speed obtained from leg power. Leg power provides strong repulsion with vertical speed so it is able to make high jumps and is able to reach the ball followed by ball service moves. Leg power is the ability of a group of muscles contained in a limb that functions to exert power during jumping in service jumping. Leap can be done because it gets a strong repulsion. The power to repel is obtained from leg power. Leg power functions as a booster boost force when performing repulsion to gain vertical speed to grab the ball in the air and over the net. The greater the force of thrust from the legs, the higher the jump and reach in the air to reach the ball that has been bolted so that a volleyball player will be able to do a good jumping service. The role of leg power to the jumping service is to apply pressure and sharpness to the shot made by jumping so that it can reach the highest ball position. Leg power that starts from the whole service movement, so that it becomes the foundation for the movement of other limbs [13]. Leg power influences the jump as a result of leg impulse. Athletes who have good leg power will be able to jump higher, and are more stable when in the air. Strong leg power will produce a hard and strong jumping service. The leg power has an influence on the jump as a result of the leg push needed when making the jump as much as possible to reach the ball in the air and over the net.

The results of the analysis of research data prove that there is a contribution of arm power to the ability to service jumping in volleyball games ( $\mathrm{p}$ value $=0.015$ ). This can be interpreted as the power of the arm contributes significantly to the ability to service jumping in volleyball games by $20.4 \%$. The arm power contributes to jumping service can be explained because arm power provides a power boost to the ball being hit. The power in the ball, the ball flow will be harder so that it can reach the target precisely. Arm power also makes the ball go fast so the ball can aim at the target [14].

Arm power provides impetus and swing power when hitting the ball. Arm power serves to provide power when making a ball hit which is flowed through the arm swing. A volleyball player will have good arm power, the greater the power given by the arm, the harder and stronger the blow given by the arm, the harder and stronger the blow given to the volleyball will produce a harder and more precise jumping service.

Power will affect an activity that requires explosive motion. The combination of strength and speed plays an important role in most sports skills. Arm power is an important factor in service jumping. Arm power will put pressure on the ball that is hit with a ball flow harder and faster, so it will be difficult to return. Arm power in service jumping has the role of producing stronger, faster and sharper service. Supported by swinging the arm inward at high speed will produce a whack during the imposition of the ball [15]

Arm power that is produced from swinging the arm inward will produce a boost in the form of force boost when the hand is in contact with the ball. Arm power will exert maximum strength with a short time. This will result in a stronger, faster and sharper service. The stronger the power of the arm, the stronger the power impulse that is channeled to the ball. The resulting service also becomes stronger and more directional. The greater the power given by the arm, the harder and stronger the blow given by the arm, the harder and stronger the blow given to the volleyball, so that it will produce jumping services that are getting harder and more precise [16]. The results of the analysis prove statistically there is a contribution of abdominal muscle strength to the ability to service jumping in volleyball games ( $\mathrm{p}$ value $=0.018$ ). These results prove that abdominal muscle strength plays a role in the ability to service jumping in volleyball games.

The abdominal muscles have a positive impact to the jumping service which can be explained by the strength produced by the abdominal muscles which put pressure on the ball being hit. The presence of abdominal muscle strength resulting from the ball service becomes harder, faster and sharper. Abdominal muscles also provide endurance that causes the service punch to be directed. Muscle strength is the amount of energy that can be expended by someone. The energy in question is the result of contraction of a muscle or group of muscles while receiving a load, both from outside and inside. The role of the abdominal muscle strength to serve is a strong abdominal muscle will put pressure on the ball that is hit so that the speed of the service ball becomes hard, fast and sharp. Strong abdominal muscles will provide endurance to remain stable when in the air so that the service ball blows 
are directed and targeted.

The role of the abdominal muscle strength to serve is a strong abdominal muscle will put pressure on the ball that is hit so that the speed of the service ball becomes hard, fast and sharp. Strong abdominal muscles will provide resistance to the strength of the abdominal muscles so that the service stroke remains directed [17]

Abdominal muscles are one important component in performing jumping services. When doing the jump, the abdominal muscles support the player's body to remain stable. Abdominal muscles also provide energy flow both when in the air and when hitting the ball. The better the strength of the abdominal muscles, the better the flow of energy provided and the better the jumping service produced. Supported by the opinion mentions the role of abdominal muscle strength in service, ie strong abdominal muscles will put pressure on the ball that is hit so that the rate of the service ball becomes hard, fast and sharp. Strong abdominal muscles will provide resistance to the strength of the abdominal muscles so that the service stroke remains directed [16].

The results of the analysis of the research data showed there was a contribution to the strength of the back muscle jumping service ability in the game of volleyball $(p$ value $=$ 0.031 ). These results can be interpreted that the strength of the back muscles has an influence on the ability to service jumping. Back muscles are faced by service jumping which is to supply energy when servicing. Energy from the back muscles will produce movement and tension which gives the effect of pounding when making a punch. The energy supply will produce jumping service with a fast and strong ball flow. Back muscles are an important component in the attitude and movement of the spine. Back muscles increase the ability to move involving the muscles of the back of the body. Back muscles also have an important role in upper body motion. The strength of the back muscles is needed when performing jumping services to deliver energy supply to the upper body. The large energy flow that results from the strength of the back muscles gives the beat when making a punch. The function of the back muscles is the same as the abdominal muscles, namely as a support and enforcement of the body so that the position remains stable when in the air. A stable body position supported by a strong flow of energy to hit the ball will produce a hard and right on-target service jump. The stronger the strength of the back muscles, the greater the supply of energy given to the upper body. Energy will also be channeled through the arm which directly hits the ball. A large supply of energy to the arm will produce power to service.

The strength of the back muscles is needed when performing jumping services to deliver energy supply to the upper body. The large energy flow that results from the strength of the back muscles gives the beat when making a punch. Energy will be channeled to the arm which is continued to hit the ball resulting in a hard-jumping service stroke [18]
When doing jumping service, it requires coordination of jumps and hard swings when floating in the air. This can only be done if the upper body is able to sustain upper body movements properly, as well as supplying energy to the ball being hit. The jumping service requires energy, one of which comes from the strength of the back muscles to produce movement, tension, and lateral so as to give a beat to a blow. The higher the level of back muscle strength, the more energy supplied upwards will produce strength in the arms to serve [19].

The results of the analysis of the research data found that there was a contribution of leg power, arm power, abdominal strength and back muscle strength to the ability to service jumping in volleyball games $(p=0,000)$. This can be interpreted that leg power, arm power, abdominal strength and back muscle strength contribute simultaneously to the ability to service jumping in volleyball games by $89 \%$ while the remaining $11 \%$ is influenced by other factors not examined in this study. The variable that most influences the ability to service jumping in volleyball is the leg power variable contributing $28.7 \%$.

The results of this study have the implication that to perform jumping services requires physical abilities that support the attitude and gestures including leg power, arm power, abdominal strength and back muscle strength. Players who have the ability in the physical component will be able to service jumping properly. The good service skills require good physical conditions. Physical condition and physical preparation can be one of the prerequisites that are very necessary in an effort to improve the achievement of an athlete.

\section{Conclusions}

There is a contribution of leg power to the ability to service jumping in volleyball games $(p$ value $=0.011)$ of $28.7 \%$. There is a contribution of arm power to the ability to service jumping in volleyball games ( $\mathrm{p}$ value $=0.015$ ) of $20.4 \%$. There was a contribution of abdominal muscle strength to the ability to service jumping in volleyball games ( $p$ value $=0.018)$ ) of $23.2 \%$. There is a contribution of back muscle strength to the ability to service jumping in volleyball games ( $p$ value $=0.031)$ ) of $16.7 \%$. There is a contribution of leg power, arm power, abdominal strength and back muscle strength to the ability to service jumping in volleyball games $(\mathrm{p}$ value $=0,000)$. The amount of contribution of leg power, arm power, abdominal strength and back muscle strength to the ability to service jumping in volleyball games is $89 \%$.

For coaches: maximize training programs to perfect jumping service capabilities by increasing leg power, arm power, abdominal strength and back muscle strength in players. For players: improving physical abilities including leg power, arm power, abdominal strength and back muscle strength to support the ability to service jumping through 
active training in accordance with the direction of the trainer. For further researchers: use the appropriate measurement instruments in accordance with the research variables in order to obtain accurate measurement results data

\section{Acknowledgement}

I am grateful to all the sport science students of Yogyakarta State University who have been pleased to be the samples.

\section{REFERENCES}

[1] E. Satriya Wijaya, T. Rahayu, A. Korespondensi, R. Prupuk Selatan, D. Prupuk Selatan, and K. Margasari Kabupaten Tegal, "Sports Evaluation Program of Female's Volleyball Achivement on Junior High School of Bantarkawung sub-district," J. Phys. Educ. Sport., vol. 7, no. 1, pp. 36-42, 2018.

[2] C. Fernandez-Echeverria, I. Mesquita, M. Conejero, and M. P. Moreno, "Perceptions of elite volleyball players on the importance of match analysis during the training process," Int. J. Perform. Anal. Sport, vol. 19, no. 1, pp. 49-64, 2019.

[3] J. M. Palao, P. Manzanares, and E. Ortega, "Techniques used and efficacy of volleyball skills in relation to gender," Int. J. Perform. Anal. Sport, vol. 9, no. 2, pp. 281-293, 2009.

[4] J. M. Palao, J. A. Santos, and A. Ureña, "Effect of team level on performance of skills in volleyball," Int. J. Perform. Anal. Sport, vol. 4, no. 2, pp. 50-60, 2004.

[5] T. Ajayati, "The Learning Model of Forearm Passing In Volleyball for Junior High School," JETL (Journal Educ. Teach. Learn., vol. 2, no. 2, p. 218, 2017.

[6] S. \& Eldawati, "Journal of Physical Education, Sport, Health and Recreations," J. Phys. Educ. Sport. Heal. Recreat., vol. 4, no. 2, pp. 1613-1620, 2015.

[7] P. A. P. Woro, T. Rahayu, and R. Setya, "The Influence of Learning Approeach and Eye-Hand Coordination on The Learning Outcomes of Mini Volleyball Passing Skill," $J$. Phys. Educ. Sport., vol. 8, no. 1, pp. 39-43, 2018.

[8] S. Kumar, J. Goswami, and A. Kumar, "Effect of Training Program on Volleyball Skills of Inter-University level Volleyball Players Effect of Training Program on Volleyball
Skills of Inter-University level,” no. March 2016, 2017.

[9] R. Hileno, A. García-De-Alcaraz, B. Buscà, C. Salas, and O. Camerino, "What are the Most Widely Used and Effective Attack Coverage Systems in Men's Volleyball?," J. Hum. Kinet., vol. 62, no. 1, pp. 111-121, 2018.

[10] G. T. Selvaganesh and S. Manikandan, "Effect of Imagery Training on Selected Skill Performance Variables of Male Volleyball Players," vol. 3, no. August, pp. 79-82, 2016.

[11] S. Hirunrat and O. Ingkatecha, "Kinematics and kinetics of jumping serve in youth national and national Thai female volleyball players of Thailand," Int. J. Sport Exerc. Sci., vol. 7, no. 1, pp. 13-16, 2015.

[12] A. I. A. Medeiros, I. M. Mesquita, R. O. Marcelino, and J. M. Palao, "Effects of technique, age and player's role on serve and attack efficacy in high level beach volleyball players," Int. J. Perform. Anal. Sport, vol. 14, no. 3, pp. 680-691, 2014.

[13] S. Qassim, M. Assistant, A. Dean, P. Education, and G. View, "Some Aspects of the Muscular Strength for the Volley Ball Players and Javelin Players in Athletics," no. June, 2016.

[14] A. F. Silva, F. M. Clemente, R. Lima, P. T. Nikolaidis, T. Rosemann, and B. Knechtle, "The effect of plyometric training in volleyball players: A systematic review," Int. J. Environ. Res. Public Health, vol. 16, no. 16, 2019.

[15] M. Syahrir, D. G. Mapato, and T. Soenyoto, "The Effect of Leg Length Plyometric Exercise on Increasing Volleyball Jump Power at Public Senior High School 1 Parigi Motong," vol. 7, no. 3, pp. 274-279, 2018.

[16] N. Nasuka and A. W. Pradana, "Squat Jump Exercise Increased Spike Jump and Block Jump Reach of Junior Volleyball Athletes," KnE Soc. Sci., vol. 2019, pp. 422-426, 2019.

[17] U. DEVRIM and K. ERDEM, "Evaluation of the Effects of Core-Quick Strength and Core-Plyometric Studies on Balance, Agility and Strength Traits of Volleyball Players," Asian J. Educ. Train., vol. 5, no. 3, pp. 482-487, 2019.

[18] J. Teixeira, P. Carvalho, C. Moreira, A. Carneiro, and R. Santos, "Muscle Strength Assessment of Knee Flexors and Extensors. Comparative Study between Basketball, Football, Handball and Volleyball Athletes," Int. J. Sport. Sci., vol. 5, no. 5, pp. 192-200, 2015.

[19] S. Bong-ju and K. Byoung-goo, "Differences of Physique and Physical Fitness among Male South Korean Elite National Track and Field Athletes," Int. J. Hum. Mov. Sport. Sci., vol. 5, no. 2, pp. 17-26, 2017. 